Driving Pressure or Tidal Pressure: What A Difference a Name Makes

\section{In Reply:}

We certainly agree that the term driving pressure is a misnomer because it is the difference between two static variables recorded at end-inspiration and end-expiration. As such, it represents the amplitude of the tidal alveolar pressure, but the only thing it "drives" is the onset of deflation. Nonetheless, that term has long been used in engineering and physiology to indicate amplitude and has taken hold in clinical practice since publication of The New England Journal of Medicine article by Amato et al $^{1}$ in 2015 . We seem to be stuck with it now as representing the

The authors have no conflicts to disclose.

Correspondence: Arianne K Baldomero MD, 1 Veterans Drive (Pulmonary 111-N), Minneapolis, MN 55417. E-mail: baldo004@umn.edu.

DOI: $10.4187 /$ respcare. 07268 quotient of externally measured and readily accessible variables: tidal volume and compliance and/or the difference between plateau pressure and total PEEP. Most competent practitioners who adjust ventilators recognize the underlying definition and meaning of that term. We took pains in our article ${ }^{2}$ to note that passive (no flow) conditions ideally must apply without muscular effort at both extremes of the tidal cycle when recording plateau and total PEEP, as Chatburn and van der Staay dutifully note. ${ }^{3}$ With regard to pressure control ventilation, we also agree that the maximum tidal airway pressure is not always static at end-inspiration. Fortunately, only an uninformed respiratory therapist would record the pressure control ventilation target as the "plateau" without confirming that flow had stopped.

We do foresee some problems with the substitute term suggested by Chatburn and van der Staay. Whether intended or not, tidal pressure, invites confusion at the bedside because it conjures up the idea of the total dynamic pressure needed to overcome both tidal resistance and elastance, which is not the alveolus-level stretch pa- rameter of primary interest. Nonetheless, we appreciate and encourage such thoughtful reflection on the current scientific literature and terminology of our field.

John J Marini Arianne K Baldomero Department of Medicine Division of Pulmonary

Allergy, Critical Care, and Sleep Medicine University of Minnesota Minneapolis, Minnesota

\section{REFERENCES}

1. Amato MB, Meade MO, Slutsky AS, Brochard L, Costa EL, Schoenfeld DA, et al. Driving pressure and survival in the acute respiratory distress syndrome. N Engl J Med 2015;372(8):747-755.

2. Baldomero AK, Skarda PK, Marini JJ. Driving pressure: defining the range: Respir Care 2019;64(8):883-889.

3. Chatburn RL, van der Staay M. Driving pressure or tidal pressure: what a difference a name makes. Respir Care 2019;64(9):11771181. 